\title{
Diagnosis, management and care of hypertensive disorders of pregnancy (HDP): An Indian Expert Opinion
}

\author{
Bhaskar Pal ${ }^{1}$, Parag Biniwale ${ }^{2}$, Hemant Deshpande ${ }^{3}$, Tripura Sundari ${ }^{4}$, Mirudhubashini Govindarajan ${ }^{5}$, Jayam \\ Kannan $^{6}$, Gorakh Mandrupkar ${ }^{7}$, Nikhil Datar ${ }^{8}$, Manish Pandya9, P. Balamba ${ }^{10}$, Ambarisha Bhandiwad ${ }^{11}$, Sheela \\ Mane $^{12}$, G. Chandravati ${ }^{13}$, Lila Vyas ${ }^{14}$, Amandeep Khurana ${ }^{15}$, Salman Motlekar ${ }^{16 *}$, Amit Qamra ${ }^{17}$, Rishi Jain ${ }^{18}$ \\ ${ }^{1}$ Senior Consultant, ${ }^{2}$ Consultant, ${ }^{3}$ Professor and Head, ${ }^{4,12}$ Consultant and HOD, ${ }^{5}$ Clinical Director, ${ }^{6}$ Cheif Consultant, ${ }^{7}$ Specialist, ${ }^{8}$ Senior \\ Medical Director, ${ }^{\mathbf{9}}{ }^{11}$ Professor and HOD, ${ }^{10}$ Senior, ${ }^{13} \mathrm{HOD}$ (Retd.), ${ }^{\mathbf{1 4}}$ Gynecologist Medical Advisor, ${ }^{\mathbf{1 5}}$ Head Medical Information, ${ }^{\mathbf{1 6}} \mathrm{Head}-$

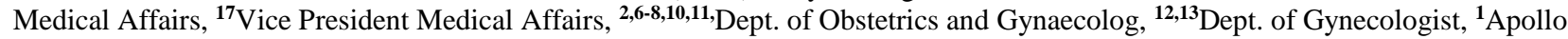 \\ Gleneagles Hospital Ltd., Kolkata, ${ }^{2}$ Biniwale Clinic, Pune, ${ }^{3}$ Dr. D. Y. Patil Medical College, Hospital \& Research Centre, Pune, ${ }^{4}$ Krishna \\ Institute of Medical Sciences, Secunderabad, ${ }^{5}$ Womens Centre, Coimbatore, ${ }^{6}$ Garbba Rakshambigai Fertility Center, Chennai, \\ ${ }^{7}$ Mandrupkar Clinic, Islampur, ${ }^{8}$ Cloudnine Hospital, Mumbai, ${ }^{9}$ Scientific Research Institute, Surendranagar, ${ }^{10}$ Shalini Hospital, Hyderabad, \\ ${ }^{11}$ JSS Medical College and Hospital, Mysore, ${ }^{12}$ Anugraha Nursing Home, Bangalore, ${ }^{\mathbf{1 3}}$ Krishna Medical Centre, Lucknow, ${ }^{14}$ SMS Medical \\ College and Hospital, Jaipur, ${ }^{15}$ Wockhardt Ltd., Medical Affairs, Mumbai, ${ }^{16}$ Wockhardt Ltd., Medical Affairs, Mumbai, ${ }^{17,18}$ Wockhardt \\ Ltd., Medical Affairs, Mumbai, Maharashtra, India
}

\section{*Corresponding author: Salman Motlekar}

Email: smotlekar@wockhardt.com

\begin{abstract}
Aim: To develop a guiding tool for the screening, diagnosis, management and care of hypertensive disorders of pregnancy (HDP) by Indian expert panel consensus.

Materials and Methods: Databases such as PubMed, Medline, the Cochrane library and Google Scholar were searched for literature on HDP. Guidelines on HDP from Sri- Lanka, Bahrain, Singapore, Malaysia, Federation of Obstetric and Gynecological Societies of India (FOGSI), Japan, Canada, Australia, US, Europe, and others were studied and discussed as reference documents. A 14 member committee of Gynecology and Obstetrics experts was formed in scientific collaboration with Wockhardt Ltd., Mumbai (India) to prepare an expert opinion on HDP for India. The panel discussed hypertension (HTN) for a) classification b) techniques of monitoring BP c) when to start antihypertensive d) diagnostic tests e) important management and type of medical care needed in pre, during and post pregnancy. The panel also compared the guidelines of different countries to discuss the differences and similarities in management of HTN mainly focusing preeclampsia (PE).

Results: The panel recommended NICE guidelines to classify HTN. The panel also advised to follow the antenatal care (ANC) guidelines and perform thorough clinical examination of the patient on first visit preferably in first trimester and then subsequent visits during the pregnancy. The panel emphasized on the measurement of BP with standard mercury sphygmomanometer in the sitting posture. Since PE has a higher incidence in India, a minimum of four antenatal care visits and initial screening (BP and proteinuria) at 8 to 12 weeks of gestation for early diagnosis of hypertension are advised. The panel suggested that the target BP should be 130-150/80-100 mm Hg on antihypertensive therapy. Either labetalol or methyldopa should be used as first line treatment during third trimester of pregnancy. However, during second trimester methyldopa should be used as the first line treatment.

Conclusion: This guiding document is an outcome of panel discussions on HDP for Indian women and health care practitioners. It will serve as a guide for obstetricians in India and help them to identify, screen, diagnose and manage women with HDP.
\end{abstract}

Keywords: Hypertensive disorders of pregnancy (HDP), Pre-eclampsia (PE), Antihypertensive agents, Pregnancy, Postpartum care, Pregnancy induced hypertension (PIH).

\section{Introduction}

\section{Prevalence of HDP}

As per the World Health Organization (WHO) 2014 report, hypertension is accounted as the second most common direct cause of maternal mortality worldwide. About 76,000 pregnant women die each year from preeclampsia (PE) and related hypertensive disorders that amounts to nearly 200 women every day. ${ }^{1}$ Women in the developed countries have an average life time risk of pregnancy related deaths of between 1 in 4000 to 1 in 10000, whereas women in developing countries have a risk that is between 1 in 15 to 1 in 50. Hypertensive disorders in pregnancy (HDP) ranks second only to hemorrhage and is a direct cause of maternal mortality. ${ }^{1}$ Women in the developing countries have a seven times higher risk to develop PE than the women in the developed countries. ${ }^{3}$

\section{Why India needs a guiding tool for HDP?}

Globally, there are many guidelines established for defining the classification, management and diagnosis of HDP. The Government of India (GoI) has a commitment under its National Rural Health Mission (NRHM)/Reproductive and Child Health (RCH)-II program to ensure universal coverage of all births with skilled attendance, both at the institutional and at the community level. GoI has published guidelines for antenatal care and skilled attendance at birth with this objective so as to meet the National and Millennium Development goals. ${ }^{5}$ There are limited studies on HDP conducted in India. As per the Indian Council of 
Medical Research (ICMR), HDP is reported in approximately $10-20 \%$ of all the pregnant women across India whereas PE incidence is reported to be $8-10 \%$. As per the national health portal, in Asia and Africa, nearly one tenth of all maternal deaths are associated with $\mathrm{HDP}^{6,7}$ In a retrospective study over the period 2000-2009 in a tertiary center in India, HDP was the third major cause of maternal deaths. ${ }^{8}$ A study conducted by the Federation of Obstetric and Gynecological Societies of India (FOGSI) reported that the majority $(51.10 \%)$ of the women died around peripartum and immediate postpartum with HDP and obstetric hemorrhage. ${ }^{9}$ Though treating HDP does not alter the progression of disease, early management decreases not only the frequency of hypertensive complications, but also the rate of neonatal complications. ${ }^{10}$ (Table 1) tabulates some of the studies on HDP that have been conducted in India. However, there is no specific document that can serve as a guide to the gynecologists and obstetricians. Since there is a lack of consensus on HDP in Indian health scenario. Thus, this guiding tool can be ready reckoner for clinicians in diagnosing \& managing women with HDP.

\section{Materials and Methods}

An expert panel of 14 obstetricians working in private \& public sector formed from India to discuss the diagnosis, management and care of HDP. Extensive literature search was conducted in PubMed, Medline, the Cochrane library and Google Scholar for articles related to HDP. Guidelines on HDP from Asia including Sri-Lanka, Bahrain, Singapore, Malaysia, Japan, FOGSI, Canada, Australia, US and Europe were reviewed and discussed as reference documents. Other guidelines, viz; Society of Obstetric Medicine of Australia and New Zealand (SOMANZ), Society of Obstetricians and Gynecologists of Canada (SOGC), Japan Society for Study of Hypertension in Pregnancy (JSSHP), American College of Obstetricians and Gynecologists (ACOG), National Collaborating Centre for Women's and Children's Health (NICE) Guidelines by RCOG (Royal College of Obstetricians and Gynecologists) and World Health Organization (WHO) were also referred. The first advisory board meeting involved discussions at length with all the members and recommendations were sought. The working draft was prepared which underwent three revisions in the subsequent meetings held at different time intervals. The revised document was then sent to the expert panel for final review and further comments and was subsequently finalized. A poster of the same was presented in Berlin at ISSHP European Congress 2017. ${ }^{10}$

\section{Questions Discussed}

Q1: What are the different types of classification for hypertension (HTN) in pregnancy?

There are several definitions given to define HDP by various guidelines. Most commonly used terms are as follows:

1. Gestational HTN: Onset of new HTN after 20 weeks of gestation and BP returns to normal by 12 weeks postpartum. No proteinuria is observed. ${ }^{11,12}$
2. Pre-eclampsia (PE): $\mathrm{PE}$ is also called as toxemia of pregnancy, a condition that typically starts after 20 weeks of gestation. Proteinuria is present along with other signs; increased BP and edema. It is more common at the extremes of maternal age $(<20 \mathrm{yr}$ or $>40 \mathrm{yr})$.

3. Severe Pre-eclampsia (PE): The usual symptoms of severe PE include persistent headache, visual disturbances, rapidly increasing generalized edema, oliguria, epigastric pain, nausea, and vomiting and chest pain. It can also occur without proteinuria, with hepatic, hematopoietic, or other manifestations. Pregnant women with HTN plus other adverse conditions but no proteinuria should have further evaluation for severe PE. ${ }^{12}$

4. Eclampsia: It is the occurrence of convulsions in association with PE, is a rare but serious complication of pregnancy. Convulsions that occur during pregnancy, delivery or in the postpartum period should be assumed to be due to eclampsia, unless proven otherwise. It is characterized by convulsions and high BP (140/90 $\mathrm{mmHg}$ or more). The pathophysiology of this disorder is not much clear. Several mechanisms have been implicated in the pathogenesis of eclampsia which includes; hypertensive encephalopathy, cerebral edema, infarction, hemorrhage, endothelial dysfunction and others. ${ }^{13-15}$

5. Chronic HTN: HTN is chronic if it is detected before 20 weeks of gestation or the individual is already diagnosed as hypertensive and/or on antihypertensive medication. It can be primary or secondary. ${ }^{16-18}$

6. Resistant HTN: It is a condition when $\mathrm{BP}$ is not controlled even after treating with at least three antihypertensives for more than 72 hours (3 days).

7. Chronic HTN and Proteinuria: It is associated with new or worsening proteinuria, one or more adverse conditions or one or more severe complications. It is associated with SBP $>160 \mathrm{mmHg}$ or DBP $>110 \mathrm{mmHg}$ on two occasions at least 4 hours apart while the patient is on bed rest (unless antihypertensive therapy is initiated before this time). It is associated with the following conditions: Thrombocytopenia (platelet count $<100,000$ ), elevated liver enzymes levels to twice the normal liver function, severe persistent right upper quadrant (RUQ) or epigastric pain unresponsive to medication and not accounted for by alternative diagnoses, or both, haemolysis, new development of renal insufficiency (elevated serum creatinine greater than $1.1 \mathrm{mg} / \mathrm{dL}$ ), pulmonary edema, onset of cerebral or visual disturbances.

8. PE superimposed upon Chronic HTN: Pre-existing HTN is a strong risk factor for the development of PE. Superimposed PE is diagnosed when a woman with chronic HTN develops one or more of the systemic features of $\mathrm{PE}$ after 20 weeks of gestation. ${ }^{12}$ 


\section{Other types of HTN}

1. Unclassified HTN: If the BP is recorded for the first time after 20 weeks of gestation, it cannot be classified into any of the above category. On repeating BP measurement after 42 days postpartum, if HTN gets resolved, it is reclassified as gestational HTN. If the BP remains elevated at this stage, a diagnosis of preexisting HTN is made. ${ }^{19}$

2. White Coat HTN: BP that is elevated in the office $(\geq$ $140 / 90 \mathrm{mmHg}$ ), but $<135 / 85 \mathrm{mmHg}$ on ambulatory or home BP monitoring. ${ }^{18,20,21}$

3. Masked HTN: BP that is normal in the office $(<140 / 90$ $\mathrm{mmHg}$ ) but elevated on ambulatory or home BP monitoring $(\geq 135 / 85 \mathrm{mmHg}) .{ }^{21}$

4. Transient HTN: An office SBP $\geq 140 \mathrm{mmHg}$ or a DBP $\geq 90 \mathrm{~mm} \mathrm{Hg}$ that is not confirmed after rest, on repeat measurement, on the same or on subsequent visits. ${ }^{20}$

5. Women with white coat, masked and transient hypertension require more frequent monitoring as they have a higher risk of developing HDP.

\section{Recommendations by the Expert Panel - Diagnosis of HDP}

The Expert Panel recommended to follow classification for HDP as per NICE Guidelines (National Collaborating Centre for Women's and Children's Health Commissioned by the National Institute for Health and Clinical Excellence), UK. [11]

1. Mild: BP- $140 / 90-149 / 99 \mathrm{~mm} \mathrm{Hg}$

2. Moderate: BP- 150/100- $159 / 109 \mathrm{~mm} \mathrm{Hg}$

3. Severe: $B P-\geq 160 / 110 \mathrm{~mm} \mathrm{Hg}$.

HTN is diagnosed when two consecutive readings taken four hours or more apart show the SBP to be $140 \mathrm{mmHg}$ or more and/or the DBP to be $90 \mathrm{mmHg}$ or more. High BP during pregnancy may signify HDP and/or chronic HTN

\section{Q2: How to measure BP in pregnant women?}

$\mathrm{BP}$ is highly variable within subjects; appropriate care must be taken to minimize various factors that may affect BP measurement, especially choice of cuff size, posture and Korotkoff sounds.

\section{Recommendations by the Expert Panel Instrument and recordings}

BP should be measured by the standard mercury / aneroid sphygmomanometer. The SBP and DBP should be measured as an average of at least two measurements taken from the same arm. ${ }^{5}$ In an office setting, when BP elevation is non-severe and $\mathrm{PE}$ is not suspected, either ambulatory $\mathrm{BP}$ monitoring (ABPM) or home BP monitoring (HBPM) is useful to confirm persistently elevated BP. Non-severely elevated BP should be confirmed by repeated measurement, at least 15 minutes apart from that visit. ${ }^{12}$

\section{Posture}

BP should be measured while sitting in a chair with feet flat on the floor and back supported, using either the right or left arm consistently. Ideally, prior to BP measurement, the patient should be undisturbed and at rest for at least 5 minutes, in a quiet room, if possible. If BP is consistently higher in one arm, the arm with the higher values should be used for all the BP measurements. ${ }^{12}$ The pressure at which the sounds are first heard (phase I) is taken to indicate the SBP. Near the DBP, the sounds first become muffled (phase IV) and then disappear (phase V). Phase V should be considered as DBP. ${ }^{22}$

\section{Important Note}

Caffeine and tobacco should be avoided for at least 30 minutes prior to the measurement. Automated machines should be avoided to measure BP as these have to be calibrated at regular intervals. Some countries use calibrated android device, or an automated BP machine that has been validated for use in PE. Automated BP machines that have not been validated or used in PE may under- or overestimate the readings ${ }^{12}$

\section{Q 3 When and how to detect HDP?}

It is crucial to diagnose HDP so that corrective measures can be taken. Since it is mostly asymptomatic, repeated BP measurements throughout the pregnancy should be made to diagnose elevated BP.

\section{Recommendations by the Expert Panel}

1. Ideally, there must be a minimum of at least four antenatal care (ANC) visits including early registration and first ANC along with the complete history and dietary advice. This should be done in the first trimester itself.

2. Risk assessment should be done for HDP and other disorders during the booking visit. It is suggested that the physician should prepare an ANC plan which should be shared with patients also during their first ANC Visit.

3. ANC plan should include list of tests to be performed and at intervals of these tests. It should ideally be made at the first ANC visit.

4. Dietary advice should be provided to the pregnant woman. Diet should be rich in iron, calcium and proteins. Calcium helps in the prevention of PE. ${ }^{5}$

5. If the woman has high $\mathrm{BP}$, she should be rechecked every 6 hours. If the BP remains high then her urine should be checked for proteinuria. The presence of proteinuria with high BP is sufficient to categorize as PE. In that case, she should be immediately referred to a specialist.

6. If a single DBP reading of the woman at any visit is above $109 \mathrm{mmHg}$, it is a danger sign and the woman should be hospitalized.

Q 4 What are the maternal and fetal risks and their diagnosis techniques?

Maternal Risks

Women who are diagnosed with either PE have the following risks in pregnancy. ${ }^{18}$ 
Cardiovascular complications: High risk to develop pulmonary edema, congestive cardiac disorders, acute left ventricular failure (ALVF), and venous thromboembolism. ${ }^{22,23}$

\section{Cerebrovascular complications}

There can be posterior reversible encephalopathy syndrome (PRES), visual disturbances such as temporary amaurosis, cerebral edema, hemorrhage and stroke associated with eclampsia. Studies show that within a period of 3 to 8 months of severe PE, some women have noticeably impaired memory which is unrelated to scores of depression, anxiety or attention. ${ }^{24,25}$

\section{Renal disease and other complications}

There is also an increased risk for women with a history of PE to develop end-stage renal disease (ESRD). A recently published study that evaluated data from the Norwegian national birth and ESRD registries found that the risk of subsequent ESRD increases with increased recurrent episodes of PE in two or more pregnancies. ${ }^{26}$ Type II diabetes, hypothyroidism and deep vein thrombosis are the other complications of PE. ${ }^{27}$

\section{Fetal Risks}

Fetus in women with both chronic hypertension and PE are at a high risk of fetal growth restriction (FGR), premature birth (iatrogenic), and perinatal death.

\section{Recommendations by the Expert Panel}

1. Accurate dating of pregnancy is important for women with chronic HTN or those at a high risk of PE.

2. Ultrasonography (USG) should be done in the third trimester for early diagnosis of fetal growth restriction (FGR).

3. Fetal surveillance is mandated in FGR and PE..$^{27-29}$

\section{Q5: What should be the management of HDP?}

The threshold level of $\mathrm{BP}$ and the decision on optimum timing to initiate an antihypertensive drug is a challenge. The panel discussed on the appropriate use of antihypertensive drugs, including therapeutic BP goals and criteria for selecting specific antihypertensive drugs.

\section{Recommendations by Expert Panel}

Target BP: Therapy is recommended in the United States for a $\mathrm{BP}$ of $\geq 160 / 105 \mathrm{~mm} \mathrm{Hg}$; with no set treatment target ${ }^{30}$ in Canada, therapy is considered at $\geq 140 / 90 \mathrm{~mm} \mathrm{Hg}$ targeting DBP to 80 to $90 \mathrm{~mm} \mathrm{Hg}{ }^{31}$ and in Australia, elevations $\geq 160 / 90 \mathrm{~mm} \mathrm{Hg}$ are treated to a target of $\geq 110$ systolic. ${ }^{32}$ Expert Panel recommended target BP-SBP:130$150 \mathrm{~mm} \mathrm{Hg}$ and DBP: 80-100 mm Hg

\section{When to start anti-hypertensives}

For mild hypertension: No drugs should be given, no hospitalization is required.

1. No need to do such a monitoring in moderate HDP.
2. Patient is admitted for BP recording \& control. BP should be checked every 4 hours.

3. For severe hypertension: Hospitalization is needed along with treatment with oral labetolol $200 \mathrm{mg}$ orally (every 4 hours, maximum $1200 \mathrm{mg} /$ day) or $40 \mathrm{mg}$ IV over 2 minutes as a first line agent till the BP falls to $\mathrm{SBP}<150 \mathrm{mmHg}$ and DBP is $80-100 \mathrm{mmHg}$

4. If BP >180/110 mmHg: Alternatives include methyldopa and nifedipine $(10 \mathrm{mg}$ orally, repeat at 20 minutes interval up to maximum $40 \mathrm{mg}$ ).

Fig. 1: shows an algorithm for managing hypertension in pregnancy in antenatal, interpartum and postpartum care.

\section{Q 6: What should be the management in special cases of HDP?}

\section{Recommendations by Expert Panel}

1. Women with pre -existing hypertension

a. Angiotensin converting enzyme inhibitors (ACEIs) inhibitors, and angiotensin receptor blockers (ARBs), and diuretics are contraindicated in second and third trimester of pregnancy.

b. Start with aspirin (75 mg OD from 12 weeks till delivery)

2. Women with chronic and gestational hypertension:

No antihypertensive has been proven safe for use during the first trimester, however panel recommended.

i. First line agent should be methyldopa ( 0.5 to 3.0 $\mathrm{g} / \mathrm{d}$ in 2 divided doses)

ii. Second line agents are labetolol (200 to $1200 \mathrm{mg} / \mathrm{d}$ in 2 to 3 divided doses) and nifedipine (30 to 120 $\mathrm{mg} / \mathrm{d}$ ) of a slow-release preparation

\section{Q 7: What should be the management of PE?}

$\mathrm{PE}$ is the most prevalent disorder amongst all HDP in India. To detect it at an early stage, following recommendations are given:

\section{Recommendations by the Expert Panel Prevention of PE}

It is desirable; however, there are no such evidences found for either specific BP targets in pregnancy or specific antihypertensive agents that modify the risk of superimposed $\mathrm{PE}$ in women with pre-existing $\mathrm{HTN} .^{33}$ Calcium: (1500-2000 mg/d - in areas with calcium poor diet) low-dose aspirin women with history of PE in previous pregnancy should be offered ${ }^{34}$

\section{Diagnosis}

Proteinuria test: In 2013, the American College of Obstetricians and Gynecologists (ACOG) removed proteinuria as an essential criterion for diagnosis of $\mathrm{PE}$, with severe features.

1. They also removed massive proteinuria (5 grams/24 hours) and Fetal Growth Restriction (FGR) as the possible features severe disease because massive proteinuria has a poor correlation with the outcome and fetal growth restriction is managed similarly whether or not $\mathrm{PE}$ is diagnosed. Oliguria was also removed as a 
characteristic of severe disease. ${ }^{12}$ The expert panel recommended that proteinuria diagnosis should be taken as a prerequisite test for every pregnant woman in the early stage of pregnancy irrespective of considering it as a sole diagnostic tool of PE detection.

2. Symptoms: Edema should not be included in the diagnostic features of PE. It is a common feature of normal pregnancy and severe PE may be present in the absence of any edema.

3. Nevertheless, rapid development of generalized edema and/or rapid weight gain should alert the clinician to screen for PE. 18,35

4. Management of PE: The management varies from BP control under supervision to delivery depending on the clinical scenario. Gestational age at which hypertension is diagnosed is an important criterion for deciding the appropriate management. Since it is a progressive disease which can be associated with other fetal and maternal risks., i.e., PE complicated by maternal seizures. ${ }^{36}$ Therefore, when antihypertensive therapy is used in women with PE, fetal monitoring is helpful to recognize any signs of fetal distress that might be attributable to reduced placental perfusion.

a. Mild PE at $37 \pm(0-7$ days $)$ weeks gestation or greater should be treated with expeditious delivery. ${ }^{37}$ Women who are diagnosed with mild PE prior to 37 weeks of gestation should be managed expectantly until they reach 37 weeks provided they undergo regular antenatal testing and maternal evaluation to monitor the fetal deterioration and/or progression to severe PE.

b. Severe PE when the onset is between 24 and 34 weeks of gestation requires complex decision making and should optimally involve a practitioner with extensive experience. Admit to hospital, observe and monitor BP, check for complications, viz; haemolysis, elevated liver enzymes and low platelets or HELLP $(\mathrm{H}=$ Haemolysis, EL $=$ Elevated liver enzymes, LP $=$ Low platelets) syndrome, pulmonary edema, seizures or cerebral hemorrhage.

c. It is suggested that corticosteroids should be administered, and the delivery should be deferred for 48 hours, if maternal and fetal conditions remain stable for women with severe PE and fetus is viable at 33 ( $\pm 6-7$ days $)$ weeks or less of gestation. But the delivery should not be delayed after an initial maternal stabilization regardless of the gestational age for women with severe PE that is further complicated with uncontrollable severe HTN, eclampsia, pulmonary edema, abruptio placentae, and intrapartum fetal demise..$^{12,19}$

\section{Q 8: What should be the management of Eclampsia? Recommendations by the Expert Panel}

Management: Mother should be monitored for BP every 30 minutes. Magnesium sulphate $\left(\mathrm{MgSO}_{4}\right)$ is the drug of choice which should be administered either through Pritchard's or
Zuspan's Regime. No other anticonvulsant should be used.

Also check for

1. Urine output: $30 \mathrm{ml} / \mathrm{hr}$, minimum $(100 \mathrm{ml} / 4 \mathrm{hrs})$

2. Patellar reflexes and respiratory rate $>16 / \mathrm{min}$,

3. If symptoms of toxicity appear, give antidote: calcium gluconate (1G IV over 10 Minutes)

4. Restrict total fluid volume (TFV) to $80 \mathrm{ml} /$ hour.

5. Avoid diuretics and NSAIDs till delivery

\section{Other Discussions \\ Comparison of HDP management with other country specific guidelines}

As per all other established International Guidelines, Methyldopa, Labetalol and Nifedipine are mostly chosen as first line agents. ACEIs and ARBs are strictly contraindicated by all the guidelines for use during pregnancy. Atenolol, prazosin and other beta blockers are also not recommended as safe during pregnancy.

(Table 2) shows the comparison of various guidelines for the treatment of HDP.

\section{Selective risk factors affecting HDP Socio Economic factors}

1. Education: Educated women are more aware about their health care services and might have lesser chances to develop HDP related complications. ${ }^{38}$

2. Socio-economic status: Women in the low income group usually ignore ailments/symptoms associated with pregnancy and cannot afford to utilize the available health care services. Therefore, the frequency of these women visiting clinics is less and they remain underdiagnosed. ${ }^{38}$

3. Geographical variations: A higher incidence of HDP is observed in rural areas. ${ }^{38}$

\section{Maternal factors}

1. Age: Women at the age of $<20$ year and $>40$ year are at a higher risk of HDP. ${ }^{38,39}$

2. Gravidity (Number of pregnancies): Women with multigravida stage (had two or more pregnancies) are at high risk of HDP in comparison to women with primigravida (in first pregnancy). ${ }^{40}$

3. Interpregnancy interval: Pregnancy interval $>7$ year and $<2$ year is at a 2 -fold increased risk of PE. ${ }^{41}$

4. Multifetal pregnancy: Twin or high order multiple pregnancies are at a higher risk for PE. ${ }^{23}$

5. Previous history of different disorders: Patients with a previous history and family background related to the complications like diabetes, polycystic ovarian disease (PCOD), renal diseases, autoimmune disorders, obesity, connective tissue disease like lupus erythematosus, rheumatoid arthritis are also at a higher risk of hypertension during pregnancy. ${ }^{38,42,43}$

6. Previous pregnancies: Cases of assisted reproductive technology (ART), mode of delivery in previous pregnancies either normal or C-section also affects $\mathrm{HDP}^{44}$ 
7. Family history of HDP: Patients who have a family history of HDP, especially in mother or sister, are at a higher risk of HDP during pregnancy ${ }^{38}$

\section{Timing of delivery and discharge in HDP patients}

Timing of delivery is dependent upon the severity of the maternal disease and the gestation at which the PE or gestational hypertension presents.

Immediate management refers to the delivery planned within 48 hours, usually after BP stabilization and corticosteroid administration to accelerate fetal pulmonary maturity. ${ }^{22}$

\section{Safe antihypertensive during pregnancy}

The aim of antihypertensive treatment is to prevent complications, such as maternal cerebral haemorrhage and eclampsia, and allow prolongation of pregnancy. According to the NICE guidelines, therapeutic goal in severe HDP is a gradual decrease of BP to $<150 / 100 \mathrm{mmHg} .{ }^{19}$ Labetalol and methyldopa as the first line and nifedipine as the second line oral treatment are used most frequently in India. As per WHO and NICE, the choice of anti-hypertensives amongst these three drugs depends on patients compliance and physicians experience and patients response. The drug can be used either singly or in various combinations. Methyldopa (pregnancy category B) is a preferred choice for non-emergent control of BP whereas; labetolol (pregnancy category C) is preferred for both emergent and non-emergent control of BP.

In India, Methyldopa has been traditionally considered as the first-line drug for HDP, owing to its safety, efficacy and low cost. However, labetalol could replace it as the first choice. ${ }^{43,45}$ Study by Sushrut et al showed that labetalol causes a sustained and smooth fall in BP and is free of the side effects of Methyldopa. ${ }^{46}$ Various studies have reported that labetalol is better tolerated than methyldopa; it improves bishop score in labor induction resulting in more efficient control of BP and may have a ripening effect on the uterine cervix. ${ }^{47}$ Some other drugs like ACE inhibitors and ARBs are fetotoxic (particularly nephrotoxic) and thus contraindicated. Prazosin may cause stillbirths. Atenolol (in contrast with other cardio-selective beta-blockers) may be associated with reduced fetal growth velocity making other agents preferable. Oral hydralazine monotherapy is generally least recommended due to maternal side effects. Calcium channel blockers (CCBs), such as nifedipine, are effective and have no major teratogenic risk. ${ }^{23,48,49}$

\section{Recommendations by the Expert Panel}

1. Either labetalol or methyldopa can be used as the first line treatment drugs during third trimester of pregnancy

2. However, during second trimester methyldopa should be used as the first line treatment

3. The alternatives include intravenous hydralazine and nifedipine.

Fig. 2. shows the safe drugs recommended to be used during pregnancy.

\section{Type of postpartum care needed}

1. Post-partum or post-natal (PNC) care is equally important. The first 48 hours after delivery are the most critical in the entire post-partum period. Most of the major complications of the postpartum period, such as HDP, primary pulmonary hypertension (PPH) and eclampsia, which can lead to maternal death, occur during this period. Hence, a woman who has just delivered needs to be closely monitored during the first 48 hours.

2. Ideally in the clinical condition of absence of continuing PE and adequate control of BP $(<150 / 100$ $\mathrm{mm} \mathrm{Hg}$ ), the woman should be discharged on the third or fourth postpartum day.

3. Patient needs follow up for a period of 2 weeks postdelivery. Antihypertensive may need to be continued for 2-6 weeks. If there are symptoms or signs of complications, the women may need to be hospitalized again. Final post-partum review at 6 week is required. If the woman is found to have raised BP (>150/100 $\mathrm{mmHg}$ ), she should be referred back to the obstetrician. ${ }^{50}$

4. As per the guidelines for antenatal care by government of India, ideally four postpartum visits are needed. First visit within 24 hours, second visit after third day of delivery, third and fourth visits are scheduled after $7^{\text {th }}$ day and 6 weeks of post-partum respectively. Three additional visits in the case of babies with low birth weight, on days 14, 21 and 28 are recommended. ${ }^{5}$

5. Choice of anti-hypertensive agents in postpartum:

a. Post-partum hypertension is common. BP typically rises after delivery over the first five days.

b. The major concern in postpartum period is the potential transfer of the drug into breast milk.

c. Most drugs safely used in pregnancy are excreted in low amounts into breast milk and are compatible with breast feeding. ${ }^{51}$

d. Methyldopa should be avoided in post-partum period.

(Table 3) lists the drugs which can be safely used during breast feeding.

\section{Solutions by the Expert Panel for the Challenges to Manage HDP in India}

Panel emphasized on following initiatives to be considered in Indian health sector to take care of pregnant women:

1. Pre-pregnancy counseling is must for every couple

2. Need of extensive clinical research is required

3. Surveillance requirement

4. Awareness programs for rural population shall be organized on regular basis

5. Antenatal care program should be a mandatory part of every registered pregnancy

6. Robust diagnostic tools should be used to detect HDP at antenatal stage

7. Appropriate training to health practitioners should be provided 
Table 1: Review of Some Indian Studies Focusing on Factors Affecting Hypertensive Disorders in Pregnancy and their Result Outcomes

\begin{tabular}{|c|c|c|c|c|c|}
\hline Year & Objective & Study & Location & Patients & Results \\
\hline $\begin{array}{l}2014 \\
{[39]}\end{array}$ & $\begin{array}{l}\text { Frequency and } \\
\text { distribution of } \\
\text { different types of } \\
\text { HDP and to assess } \\
\text { the drug utilization } \\
\text { pattern of } \\
\text { antihypertensive } \\
\text { drugs. }\end{array}$ & Prospective & $\begin{array}{c}\text { Bharati } \\
\text { Hospital, } \\
\text { Pune }\end{array}$ & $\begin{array}{c}\text { Number }(\mathrm{n}): 1330 \\
\text { pregnant women } \\
\text { Age: } 18-30 \text { years }\end{array}$ & $\begin{array}{l}\text { Overall Prevalence for HDP: } \\
7.8 \% \text {. } \\
\text { Prevalence in all types of HTN: } \\
\text { PE: } 5.6 \% \\
\text { Gestational HTN: } 1.5 \% \\
\text { Chronic HTN: } 0.15 \% \\
\text { Eclampsia: } 0.60 \% \\
\text { Determinants contributing prevalence of } \\
\text { HDP } \\
\text { Age: } 41.3 \% \text { in } 18-22 \text { years } \\
\text { Number of pregnancies: } 53.8 \% \text { primigravidae } \\
\text { patients } \\
\text { Effective drug therapy } \\
\text { methyldopa - commonest prescribed } \\
\text { antihypertensive as monotherapy (17.3\%) as } \\
\text { well as in combination therapy (i.e. } 28.8 \% \\
\text { with methyldopa and nifedipine) }\end{array}$ \\
\hline $\begin{array}{c}2012- \\
13 \\
{[52]}\end{array}$ & $\begin{array}{l}\text { Fasting lipid } \\
\text { profile and } \\
\text { atherogenic indices } \\
\text { in women } \\
\text { diagnosed with PE }\end{array}$ & $\begin{array}{l}\text { Case } \\
\text { control }\end{array}$ & $\begin{array}{l}\text { Guwahati } \\
\text { Medical } \\
\text { College and } \\
\text { Hospital, } \\
\text { Guwahati, } \\
\text { Assam }\end{array}$ & $\begin{array}{l}\text { Treated group: } \mathrm{n}= \\
50 \mathrm{PE} \text { patients who } \\
\text { were in third } \\
\text { trimester of } \\
\text { pregnancy, Control } \\
\text { group: } \mathrm{n}=50\end{array}$ & $\begin{array}{l}\text { Significant }(\mathrm{p}<0.0001) \text { increase in AIP, CRR } \\
\text { and AC; Significant correlation of SBP with } \\
\text { AIP }(\mathrm{r}=0.3583), \mathrm{CRR}(\mathrm{r}=0.3137), \text { AC } \\
(\mathrm{r}=0.3193) \text { Significant correlation between } \\
\text { gestational age and atherogenic indices in } \\
\text { treated group }\end{array}$ \\
\hline $\begin{array}{l}2006 \\
{[40]}\end{array}$ & $\begin{array}{l}\text { Determinants of PE } \\
\text {. }\end{array}$ & $\begin{array}{l}\text { Case } \\
\text { control }\end{array}$ & $\begin{array}{l}\text { District } \\
\text { Lady } \\
\text { Goschen } \\
\text { Hospital, } \\
\text { Karnataka }\end{array}$ & $\begin{array}{c}\text { PE pregnant } \\
\text { women }(n=100)\end{array}$ & $\begin{array}{l}\text { Significant determinants affecting PE were } \\
\text { BMI: } \geq 25, \text { Multiple pregnancies, }(\mathrm{p}=0.04) \\
\text { Multigravida, }(\mathrm{p}=0.07) \text { History of chronic HTN } \\
\text { ( } \mathrm{p}=0.02) \text {, History of diabetes }(\mathrm{p}=0.05), \\
\text { History of renal disease }(\mathrm{p}=0.04), \text { Family } \\
\text { history of HTN ( }=0.04)\end{array}$ \\
\hline
\end{tabular}

HDP: Hypertensive disorders in pregnancy, AIP: Atherogenic index of plasma, CRR: Cardiac risk ratio, AC: Atherogenic coefficient, SBP: Systolic blood pressure, PE: Preeclampsia, BMI: Body mass index

Table 2: Comparison of Country Specific Guidelines for the Management of Hypertensive Disorders in Pregnancy

\begin{tabular}{|c|c|c|c|}
\hline \multicolumn{4}{|c|}{ Country Specific Guidelines } \\
\hline & First line agents & $\begin{array}{c}\text { Drugs to be } \\
\text { avoided strictly }\end{array}$ & $\begin{array}{c}\text { Other contraindicated } \\
\text { drugs }\end{array}$ \\
\hline $\begin{array}{l}\text { American College of Obstetricians } \\
\text { and Gynecologists (ACOG) and } \\
\text { Island Peer Review Organization } \\
\text { (IPRO), New York - } 2013 \\
\text { Guidelines [12,20] }\end{array}$ & $\begin{array}{l}\text { labetolol and methyldopa } \\
\text { If labetalol fails, nifedipine is used } \\
\text { in patients with chronic } \\
\text { hypertension }\end{array}$ & atenolol & ACEIs and ARBs \\
\hline Canadian Guidelines (SOGC) [22] & $\begin{array}{l}\text { For severe HTN: nifedipine short- } \\
\text { acting capsules, parenteral } \\
\text { hydralazine, or parenteral labetalol } \\
\text { For Non-severe HTN: methyldopa } \\
\text { ( } 250 \text { to } 500 \mathrm{mg} \text { po bid-qid), } \\
\text { labetalol ( } 100 \text { to } 400 \mathrm{mg} \text { po bid- } \\
\text { tid, other beta-blockers } \\
\text { (acebutolol, metoprolol, pindolol, } \\
\text { and propranolol), and calcium } \\
\text { channel blockers (nifedipine XL). }\end{array}$ & $\begin{array}{l}\text { atenolol and } \\
\text { prazosin }\end{array}$ & ACEIs and ARBs \\
\hline $\begin{array}{l}\text { Society of Obstetric Medicine of } \\
\text { Australia and New Zealand } \\
\text { (SOMANZ) } 2014 \text { Guidelines) [27] }\end{array}$ & $\begin{array}{l}\text { labetalol (100-400mg } \\
\text { q8h) methyldopa ( } 250-750 \mathrm{mgtds}) \\
\text { and oxprenolol (20-160 mgq } 8 \mathrm{~h})\end{array}$ & & ACEIs and ARBs \\
\hline $\begin{array}{l}\text { Japan Society for } \\
\text { Study of Hypertension in } \\
\text { Pregnancy (JSSHP) Guidelines - }\end{array}$ & $\begin{array}{l}\text { Oral hydralazine and/or } \\
\text { methyldopa. } \\
\text { Continuous intravenous }\end{array}$ & & ACEIs and ARBs \\
\hline
\end{tabular}




\begin{tabular}{|l|l|c|c|}
\hline 2009[42] & $\begin{array}{l}\text { administration of hydralazine or } \\
\text { nicardipine for acute hypertensive } \\
\text { attack medications should be } \\
\text { administered }\end{array}$ & \\
\hline African Guidelines [53] & Methyldopa & $\begin{array}{c}\text { beta blockers and } \\
\text { diuretics }\end{array}$ & $\begin{array}{c}\text { ACEIs, ARBs } \\
\text { Diuretics beta blockers }\end{array}$ \\
\hline $\begin{array}{l}\text { Asian (MOH) Guidelines } \\
\text { (Baharain, Malaysia and } \\
\text { Singapore, Srilanka) [48,54,55] }\end{array}$ & Methyldopa and labetalol & $\begin{array}{c}\text { beta blockers and } \\
\text { diuretics }\end{array}$ & $\begin{array}{c}\text { ACEIs and ARBs } \\
\text { diuretics }\end{array}$ \\
\hline Australian Guidelines [18] & Methyldopa labetalol & beta blockers & ACEIs and ARBs \\
\hline
\end{tabular}

ACEIs: angiotensin-converting enzyme inhibitors, ARB: angiotensin II receptor blocker

Table 3: Safe Antihypertensive Drugs during Breast Feeding.

\begin{tabular}{|c|c|c|}
\hline Pharmacological Class & Safe Drugs & Contraindicated / Unsafe Drugs \\
\hline Beta blockers & $\begin{array}{l}\text { propranolol, metaprolol, avoid atenolol as there } \\
\text { is significant accumulation in breast milk. } \\
\text { Caution should be exercise when Atenolol } \\
\text { tablets is administered during pregnancy or to a } \\
\text { woman who is breast feeding }\end{array}$ & \\
\hline Calcium channel blockers & $\begin{array}{l}\text { nifedipine, lesser data available on } \\
\text { diltiazem and verapamil- may be safe, avoid } \\
\text { other calcium channel blockers. }\end{array}$ & \\
\hline ACE inhibitors & captopril, enalapril & \\
\hline $\begin{array}{l}\text { Angiotensin receptor } \\
\text { blockers }\end{array}$ & & $\begin{array}{l}\text { azilsartan, candesartan eprosartan, } \\
\text { irbesartan, losartan, olmesartan }\end{array}$ \\
\hline Thiazide diuretics & & $\begin{array}{l}\text { chlorothiazide } \\
\text { - } \quad \text { chlorthalidone, } \\
\text { hydrochlorothiazide } \\
\text { - } \quad \text { Indapamide. }\end{array}$ \\
\hline Others & methyldopa, hydralazine & \\
\hline
\end{tabular}

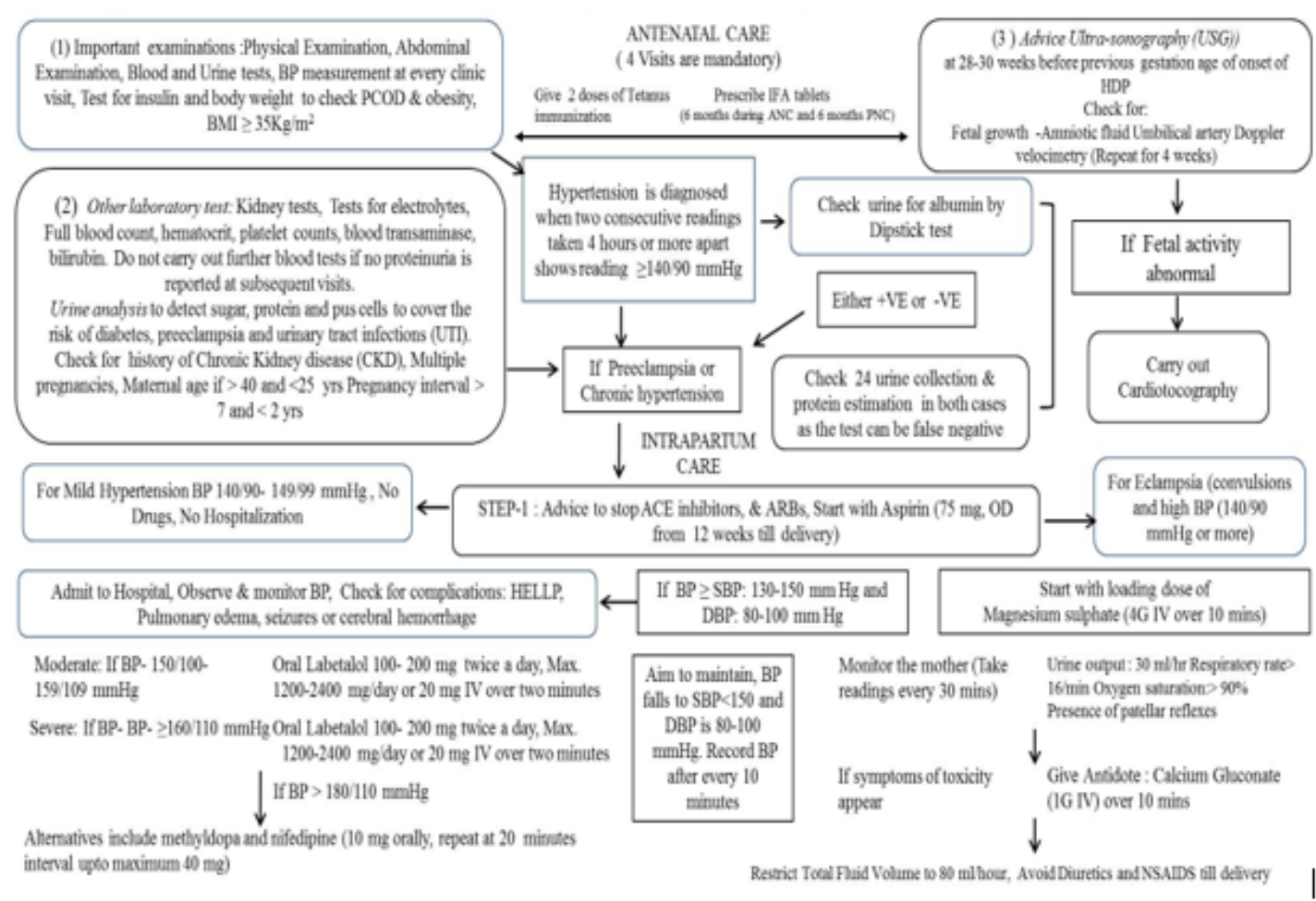

Fig. 1: Algorithm to Treat HDP in Antenatal and Interpartum Care 
a: Iron/Folic acid, ${ }^{b}$ : IM Pritchard: Loading dose is $40 \mathrm{~g}$ (20\% solution) IV over 3-5 min followed by $10 \mathrm{~g}$ (50\%) deep IM (5g in each buttock): Maintenance dose is $5 \mathrm{~g}(50 \%)$ IM 4 hourly in alternate buttock, ${ }^{c}$ : IV Zuspan: Loading dose is 4-6g IV slow over 5-10 min; Maintenance dose is 1-2 g /hr IV infusion, HTN: hypertension

\section{First Line Drugs}

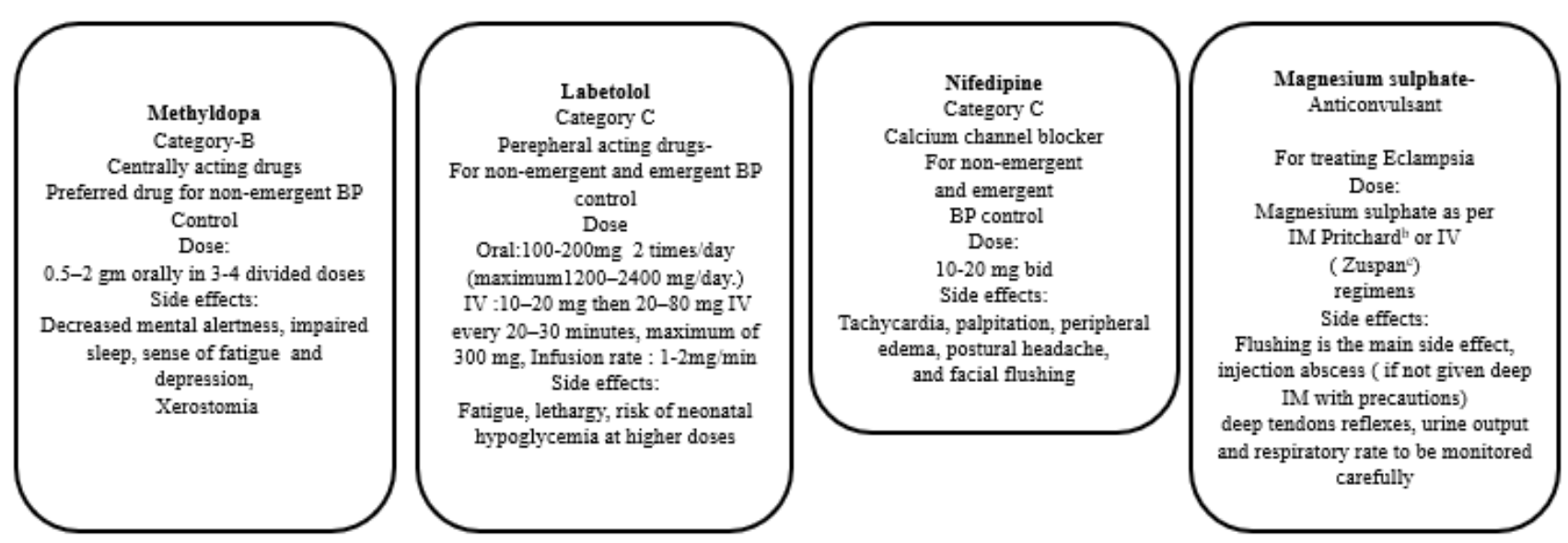

Second Line Drug

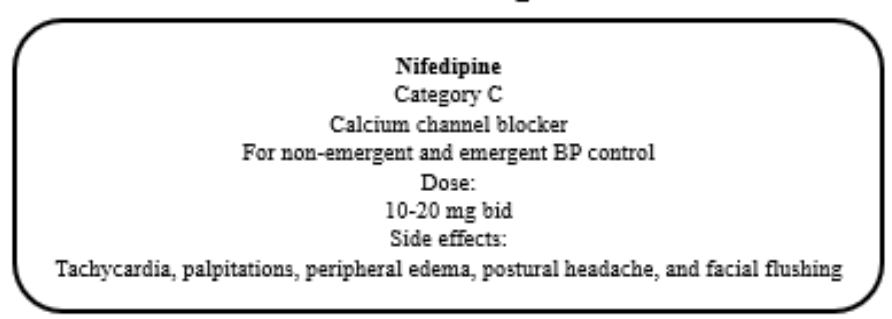

Fig. 2: Safe Antihypertensive Drugs to be used During Pregnancy

Methyldopa is recommended as the first line treatment drug during second and third trimester of pregnancy. Labetalol is recommended as the first line treatment drug during third trimester of pregnancy only. Nifedipine is the alternative drugs to be used in second trimester

\section{No Drug is considered to be safe in first trimester of pregnancy}

\section{Conclusion}

HDP has a high incidence in India. Therefore, pregnant women at the risk of HDP should be identified and high quality antenatal care should be provided to such women. Choice of a safe antihypertensive; methyldopa and labetalol as recommended by the panel is important in the management of women with HDP. Also, there is a need to strengthen the maternal health programs and to develop comprehensive guidelines for HDP focusing on prevention, early diagnosis and management in order to reduce the morbidity and mortality arising out of the disease.

\section{Acknowledgement}

The authors acknowledge Knowledge Isotopes Pvt. Ltd. (http://www.knowledgeisotopes.com) for the medical writing support.

\section{Conflict of Interest}

None of the authors have any conflicts of interest to declare. Rishi Jain, Amit Qamra, Salman Motlekar and Amandeep
Khurana are salaried employees of Wockhardt Ltd., Mumbai (India).

\section{Source of Funding}

The scientific and financial support for the conduct of expert group meetings was provided by Wockhardt Ltd., Mumbai.

\section{Copy Right Statement}

The article does not include any third- party material or any material which require permission to reproduce work under copyright.

\section{References}

1. Say L CD, Gemmill A,et al. Global causes of maternal death: a WHO systematic analysis. Lancet Glob Health 2014;;2(6):e323-33.

2. Balancing the scales: expanding treatment for pregnant women with life-threatening hypertensive conditions in developing countries. A report on barriers and solutions to treat preeclampsia and eclampsia. EngenderHealth. 2007.

3. Pre-eclampsia and maternal mortality: global burden. Available at: http://www.pre-eclampsia.org/health- 
information/149-advocacy-awareness/332-pre-eclampsia-andmaternal-mortality-a-global-burden. 2013.

4. Duley L. Maternal mortality associated with hypertensive disorders of pregnancy in Africa, Asia, Latin America and the Caribbean. Br J Obstet Gynaecol 1992;99(7):547-53.

5. RCOG: Guideline No: 10 (A)-The Management of severe Preeclampsia/ eclampsia.. In: Gyanecologists(RCOG) RCoOa, editor. 2010.

6. ICMR.: Assessment of burden of non-communicable diseases in India. Final report of Project WR/SE IND RPC 001 RB 02. SE/02/419575. New Delhi: Indian Council of Medical Research; 2004. 2004.

7. Preclampsia Report in National Health Portal. Available at URL: https://www.nhp.gov.in/disease/gynaecology-andobstetrics/preeclampsia. Last accessed on 9th Feb 2018. 2016

8. Khumanthem PD, Chanam MS, Samjetshabam RD. Maternal mortality and its causes in a tertiary center. J Obstet Gynaecol India 2012;62(2):168-71.

9. Konar H, Chakraborty AB. Maternal mortality: a FOGSI study (based on institutional data). J Obstet Gynecol India 2013;63(2):88-95.

10. Pal B, Biniwale P, Sundari T. P 4 Diagnosis, management and care of hypertensive disorders of pregnancy (HDP) in IndiaAn Indian Expert Opinion. Pregnancy Hypertens: Int J Women's Cardiovas Health 2017;9:38-9.

11. NICE Clinical Guideline: Hypertension in pregnancy the management of hypertensive disorders during pregnancy. In: Excellence NIfHaC, editor. London: Royal College of Obstetricians and Gynaecologists; 2010.

12. Hypertension in Pregnancy. Guidelines by ACOG Task Force. Obstetrics and Gynecology. 2013;122(5).

13. Guidelines for Antenatal care and skilled attendance at Birth by ANMs/LHVs/SNs. In: Maternal Health Division MoHaW, Govt. of India, editor. India. 2010.

14. Duley L, Henderson-Smart DJ, Chou D. Magnesium sulphate versus phenytoin for eclampsia. The Cochrane Library. 2010.

15. Vaisbuch E, Whitty JE, Hassan SS, et al. Circulating angiogenic and antiangiogenic factors in women with eclampsia. Am J Obstet Gynecol 2011;204(2):152. e1-e9.

16. Khumanthem PD, Chanam MS, Samjetshabam RD. Maternal mortality and its causes in a tertiary center. J Obstet Gynecol India 2012;62(2):168-71.

17. RCOG: Guideline No: 10 (A)-The Management of severe Preeclampsia/ eclampsia.. In: Gyanecologists (RCOG) RCoOa, editor.. 2010.

18. South Australian Perinatal Practice Guidelines (SAPPG): Hypertensive disorders in pregnancy. In: Department of Health GoSA, editor. South Australia2012.

19. Rahul Mehrotra MB, Ravinder S. Sambi, Krishna CK. Hypertension in pregnancy: Challenges and solutions. Indian Heart J 2010;62:423-6.

20. Hypertension in Pregnancy (Report of the ACOG Task Force on Hypertension in Pregnancy). Obstet Gynecol 2013;122(5).

21. Giuseppe, Grassi G, Parati G, et al. White Coat Hypertension: An Unresolved Diagnostic and Therapeutic Problem. 2015.

22. Magee LA, Pels A, Helewa M, Rey E, von Dadelszen P, Audibert $\mathrm{F}$ et al. Diagnosis, evaluation, and management of the hypertensive disorders of pregnancy: executive summary. $J$ Obstet Gynaecol Can 2014 May 1;36(5):416-38.

23. Reem Mustafa A, Anu Gupta, and Rocco C. Venuto. A Comprehensive Review of Hypertension in Pregnancy. $J$ Pregnancy 2012:1-19.

24. Mustafa R, Ahmed S, Gupta A. A comprehensive review of hypertension in pregnancy. J Pregnancy. 2012;2012.

25. Aukes AM, Wessel I, Dubois AM. Self-reported cognitive functioning in formerly eclamptic women. Am J Obstet Gynecol 2007;197(4):365. e1-e6.
26. B. E. Vikse LMI, T. Leivestad, R. Skjærven. Preeclampsia and the risk of end-stage renal disease. England $\mathrm{J}$ Med 2008;359:800-9.

27. Lowe S, Bowyer L, Lust K. The Management of Hypertensive Disorders of Pregnancy. The recommendations of the Society of Obstetric Medicine of Australia and New Zealand SOMANZ. 2014.

28. James PR, Nelson-Piercy C. Management of hypertension before, during, and after pregnancy. Heart 2004;90(12):1499504.

29. South Australian Perinatal Practice Guidelines (SAPPG): Hypertensive disorders in pregnancy. In: Department of Health GoSA, editor. South Australia. 2012.

30. Report of the National High Blood Pressure Education Program Working Group on High Blood Pressure in Pregnancy. Am J Obstet Gynecol 2000;183(1):S1-S22.

31. Helewa ME, Burrows RF, Smith J. Report of the Canadian Hypertension Society Consensus Conference: 1. Definitions, evaluation and classification of hypertensive disorders in pregnancy. Can Med Assoc J 1997;157(6):715-25.

32. Brown M, Hague W, Higgins J. The detection, investigation and management of hypertension in pregnancy: full consensus statement. Aust New Zealand J Obstet Gynaecol 2000;40(2):139-55.

33. Abalos E, Duley L, Steyn DW. Antihypertensive drug therapy for mild to moderate hypertension during pregnancy. The Cochrane Library. 2007.

34. Vyas KM, Vyas AK. The study of role of aspirin and antioxidants in prevention of hypertensive disorders in primigravidas. Int J Biomed Adv Res 2014;5(12):595-9.

35. Homer CS, Brown MA, Mangos G. Non-proteinuric preeclampsia: a novel risk indicator in women with gestational hypertension. J Hypertens 2008;26(2):295-302.

36. Fonseca EB, Celik E, Parra M. Progesterone and the risk of preterm birth among women with a short cervix. England $J$ Med 2007;357(5):462-9.

37. Wagner M. What every midwife should know about ACOG and VBAC. Critique of ACOG Practice Bulletin \#5, July 1999, "Vaginal birth after previous cesarean section". Midwifery Today Int Midwife 2001(59):41-3.

38. Shikha Saxena PCS, K. V. Thimmaraju, Ayaz K. Mallick, Kanchan Dalmia, Biswajit Das. Socio-demographic Profile of Pregnancy Induced Hypertension in a Tertiary Care Centre Scholars. J Appl Med Sci 2014;2(6 (D)):3081-86.

39. Sutapa Agrawal GKW. Prevalence and risk factors for Preeclampsia in Indian women: a national cross sectional study In: South Asia Network for Chronic Disease PHFoI, New Delhi, India, editor. India2005.

40. Ganesh KS, Unnikrishnan B, Nagaraj K. Determinants of Preeclampsia: A Case-control Study in a District Hospital in South India. Indian J Community Med 2010;35(4):502-5.

41. Zhang J. Partner change, birth interval and risk of preeclampsia: a paradoxical triangle. Paediatr Perinat Epidemiol 2007;21(1):31-5.

42. Naruse K, Suzuki Y, Nakamoto O, Makino S, Metoki H, Mimura K, Miyake H, Morikawa M, Murayama T, Nohira T, Ohno Y. A Brief Review of the 2009 JSSHP Guidelines for the care and treatment of Pregnancy induced Hypertension. Hypertens Res Pregnancy 2013;1(1):5-7.

43. Subhedar V, Inamdar S, Hariharan C. Comparison of efficacy of labetalol and methyldopa in patients with pregnancyinduced hypertension. Int J Reprod Contracept, Obstet Gynecol 2016;2(1):27-34.

44. Parmar MT, Solanki HM, Gosalia VV. Study of risk factors of perinatal death in pregnancy induced hypertension (PIH). Natl J Community Med 2012;3(4):703-7.

45. Vidhyasagar V. Is Labetalol or Methyldopa a better 1st line antihypertensive drug in the management of hypertension in 
preeclampsia? Available at URL:

https://www.researchgate.net/post/Is_Labetalol_or_Methyldop a_a_better_1st_line_antihypertensive_drug_in_the_manageme nt_of_hypertension_in_preeclampsia. Accessed on 2 July 2018. 2013.

46. Sushrut D GA. Labetalol - An Emerging First-line Drug for Pregnancy-induced Hypertension. Indian J Clin Pract 2013;23()

47. Lamming G, Pipkin FB, Symonds E. Comparison of the alpha and beta blocking drug, labetalol, and methyl dopa in the treatment of moderate and severe pregnancy-induced hypertension. Clin Exp Hypertens 1980;2(5):865-95.

48. Kintiraki E PS, Kotronis G, Goulis DG, Pregnancy-Induced hypertension.. Hormones. 2015;14(2):211-23.

49. Rakusan K. Drugs in pregnancy: implications for a cardiologist. Exp Clin Cardiol 2010;15(4):e100.

50. Tan LK, de Swiet M. The management of postpartum hypertension. BJOG 2002;109(7):733-6.

51. Hypertensive disorders of pregnancy. Aust Prescr 2012. 2012:47-50

52. Singh M, Pathak MS, Paul A. A Study on Atherogenic Indices of Pregnancy Induced Hypertension Patients as Compared to
Normal Pregnant Women. J Clin Diagn Res 2015;9(7):BC058.

53. Seedat Y, Rayner B. South African hypertension guideline 2011: guideline. S Afr Med J 2012;102(1):60-83.

54. National Guidelines for Maternal Care, Srilanka, Colombo, Ministry of Health 2013. Available at URL:

file:///C:/Users/admin/Downloads/national_guideline_for_mate rnalcare_1\%20(1).pdf. Last accessed on: 21 Feb 2018. 2013.

55. Sajith M, Nimbargi V, Modi A, et al. Incidence of pregnancy induced hypertension and prescription pattern of antihypertensive drugs in pregnancy. Int J Pharma Sci Res 2014;23:4.

How to cite this article: $\mathrm{Pal} \mathrm{B}$, Biniwale $\mathrm{P}$, Deshpande $\mathrm{H}$, Sundari T, Govindarajan M, Kannan J, Mandrupkar G, Datar N, Pandya M, Balamba P, Bhandiwad A, Mane S, Chandravati1 G, Vyas L, Khurana A, Motlekar S, Qamra A, Jain R, Diagnosis, management and care of hypertensive disorders of pregnancy (HDP): An indian expert opinion. Indian J Obstet Gynecol Res 2019;6(2):122-132. 